\title{
IMPORTANCIA CULTURAL DE LA FLORA EMPLEADA POR EL POBLADOR DEL DISTRITO DE SIMBAL, TRUJILLO, LA LIBERTAD - PERÚ
}

\section{CULTURAL IMPORTANCE OF THE FLORA USED BY THE RESIDENT OF THE SIMBAL DISTRICT, TRUJILLO, LA LIBERTAD - PERU}

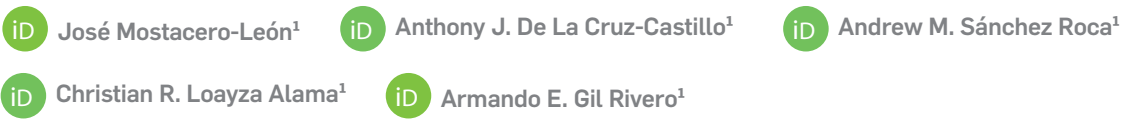

${ }^{1}$ Universidad Nacional de Trujillo, Perú.

Correspondencia:

Dr. José Mostacero-León

jmostacero@unitru.edu.pe

\section{RESUMEN}

Perú es un país megadiverso, con miles de especies nativas, y rico en saberes tradicionales provenientes en su mayoría de las culturas andino-amazónicas, legado de generación en generación a través de la experiencia, la observación y la palabra. A pesar de eso es notorio el escaso registro, preservación y difusión de dicho saber. Por ello, la presente investigación se abocó a determinar la importancia cultural de la Flora empleada por el poblador del distrito de Simbal, Trujillo, La Libertad - Perú. Para ello, se aplicaron un total de 93 entrevistas que buscaron recabar información referente a los caracteres taxonómicos y etnobotánicos de las especies empleadas por el poblador de este distrito; lográndose registrar, un total de 125 especies, enmarcadas dentro de nueve categorías de uso; y distribuidas en 104 géneros y 45 familias, donde las Leguminosae (14 especies), Solanaceae (11 especies), Compositae (8 especies) y Poaceae (8 especies), fueron las más representativas por su número de especies. Se concluye que las especies de flora más importantes para la Comunidad de Simbal son Zea mays "maíz", Zingiber officinale "kion", Allium sativum "ajo", Melia azedarach "cinamomo", Piper aduncum "matico", Persea americana "palta", Matricaria chamomilla "manzanilla", Opuntia ficus-indica "tuna", Rosmarinus officinalis "romero" y Pinus patula "pino".

Palabras clave: Importancia cultural, conocimiento ancestral, etnobotánica, Simbal, Perú.

\section{ABSTRACT}

Peru is a megadiverse country, with thousands of native species, and rich in traditional knowledge coming mostly from the Andean-Amazonian cultures, a legacy from generation to generation through experience, observation and words. Despite this, the scarce record, preservation and dissemination of said knowledge is notorious. For 
this reason, the present investigation focused on determining the cultural importance of the Flora used by the resident of the Simbal district, Trujillo, La Libertad - Peru. For this, a total of 93 interviews were applied that sought to gather information regarding the taxonomic and ethnobotanical characters of the species used by the inhabitants of this district; being able to register a total of 125 species, framed within nine categories of use; and distributed in 104 genera and 45 families, where the Leguminosae (14 species), Solanaceae (11 species), Compositae (8 species) and Poaceae (8 species), were the most representative for their number of species. It is concluded that the most important flora species for the Simbal Community are Zea mays "corn", Zingiber officinale "kion", Allium sativum "garlic", Melia azedarach "cinamomo", Piper aduncum "matico", Persea americana "avocando" , Matricaria chamomilla "chamomile", Opuntia ficus-indica "tuna fruit", Rosmarinus officinalis "rosemary" and Pinus patula "pine".

Key words: Cultural importance, ancestral knowledge, ethnobotany, Simbal, Peru.

\section{INTRODUCCIÓN}

Perú es un país megadiverso, con miles de especies nativas, debido principalmente a tres factores: la proximidad al Ecuador, una masa de agua de bajas temperaturas y la Cordillera de los Andes, originando una gran biodiversidad asentada en la enorme variedad de niveles ecológicos existentes; estos factores conllevan a que sea considerado como una zona de alta riqueza en Sudamérica (Brack, 2013; Mostacero, 2017; Britto, 2017; Ulloa et al., 2017).

Esta gran diversidad está presente tanto en la fauna como en la flora, en esta última, 18652 especies de flora (10\% del total mundial) de las cuales un $30 \%$ son endémicas, es el primero en el ranking de países de especies de plantas (4400) con propiedades conocidas y primero en especies nativas domesticadas (128) (Ulloa et al., 2017), asimismo, es el primer país en variedades de papa, ajíes, granos, tubérculos y raíces andinos, cuenta con 623 especies frutales, plantas medicinales 1408 especies, ornamentales 1600 especies, plantas alimenticias 1200 especies y se calcula entre 2600 y 3000 especies de orquídeas, lo cual hace que ocupe uno de los primeros lugares en el ranking mundial (Ulloa et al., 2004; Smith et al., 2005; León et al., 2006).

De todo ello, es importante resaltar la enorme importancia cultural de nuestra flora, estudiada por la etnobotánica, la cual posee su origen desde épocas ancestrales, y donde los antiguos amautas, hampicamayoc, oquetlupuc, sircat y boticarios, supieron muy bien emplearlas, para suplir sus necesidades básicas de alimento, vestido, medicina, tintes, bebidas, transporte, maderera, entre otros; y que hoy gracias a la ciencia y a la tecnología ha contribuido al desarrollo y posterior surgimiento de las culturas peruanas (Ford, 1978; Rostworowski, 1979; Constanza et al., 1997; Caniago y Siebert, 1998; Gonzáles, 2001; Diamond, 2002; Calderón, 2011; Hill, 2011; Medina, 2011; Mostacero et al. 2011; Sánchez, 2011; Amjad, 2015; De La Cruz \& Mostacero, 2019; Mostacero et al. 2019).

Por lo descrito, es condición necesaria tomar acciones que permita rescatar el conocimiento de nuestros ancestros sobre el correcto uso de la flora, no solo con el propósito de conservar este amplio legado, sino; con el fin de, servir a la ampliación del conocimiento científico al dar pie a nuevos métodos, usos y aprovechamientos de las especies botánicas, evidenciando en ello la interrelación del ser humano con su medio ambiente y los múltiples beneficios que trae para las poblaciones (Mostacero et al., 2009; Idolo et al., 2010; Calderón, 2011; Mostacero et al., 2011; Castañeda \& Albán, 2016; Mostacero et al., 2017).

En ese sentido, la flora del distrito de Simbal es de suma importancia debido al uso que le da el poblador en los diferentes aspectos de su vida diaria; pero que lamentablemente corre el riesgo de desaparecer, toda vez que es notorio el deficiente registro, preservación y difusión de este conocimiento ancestral, aún 
más es incierto el impacto que brindan estas especies hacia las poblaciones, esto debido a la falta de investigaciones capaces de identificar la interrelación que existe entre las diferentes especies de flora y las poblaciones aledañas, a fin de buscar su uso sustentable y sostenible (Sheldon et al., 1997; Sagástegui et al., 1999; Gomez - Beloz, 2002; Weigend, 2004; Sanjinés et al., 2006; Hill, 2011; Padilla, 2013; Castañeda y Albán, 2016).

Por lo que la presente investigación se abocó a determinar la importancia cultural de la Flora empleada por el poblador del distrito de Simbal, Trujillo, La Libertad - Perú; al ser imprescindible sentar un registro para posteriores investigaciones que permita salvaguardar este legado ancestral.

\section{MATERIALES Y MÉTODOS Lugar de ejecución}

La presente investigación se realizó en el distrito Simbal, localizado a 32 kilómetros al NE de la ciudad de Trujillo, perteneciente al valle Santa Catalina en la Región La Libertad a 0758`21" L.S. y 78ํ8'36" L.O. con elevación de 576 m s.n.m. de terreno franco-arenoso y arenoso-pedregoso, además de herbazales en áreas elevadas y yermos en los cuales se puede observar una gran variedad florística (Barces, 1989; Ancajima, 1993; Weigend, 2004; Mostacero et al., 2007; Padilla, 2013); y que cuenta con un clima semitropical y temperaturas que van desde los $15^{\circ} \mathrm{C}$ hasta los $30^{\circ} \mathrm{C}$ (Briceño \& Billman, 2009; Briceño \& Billman, 2012, Padilla, 2013).

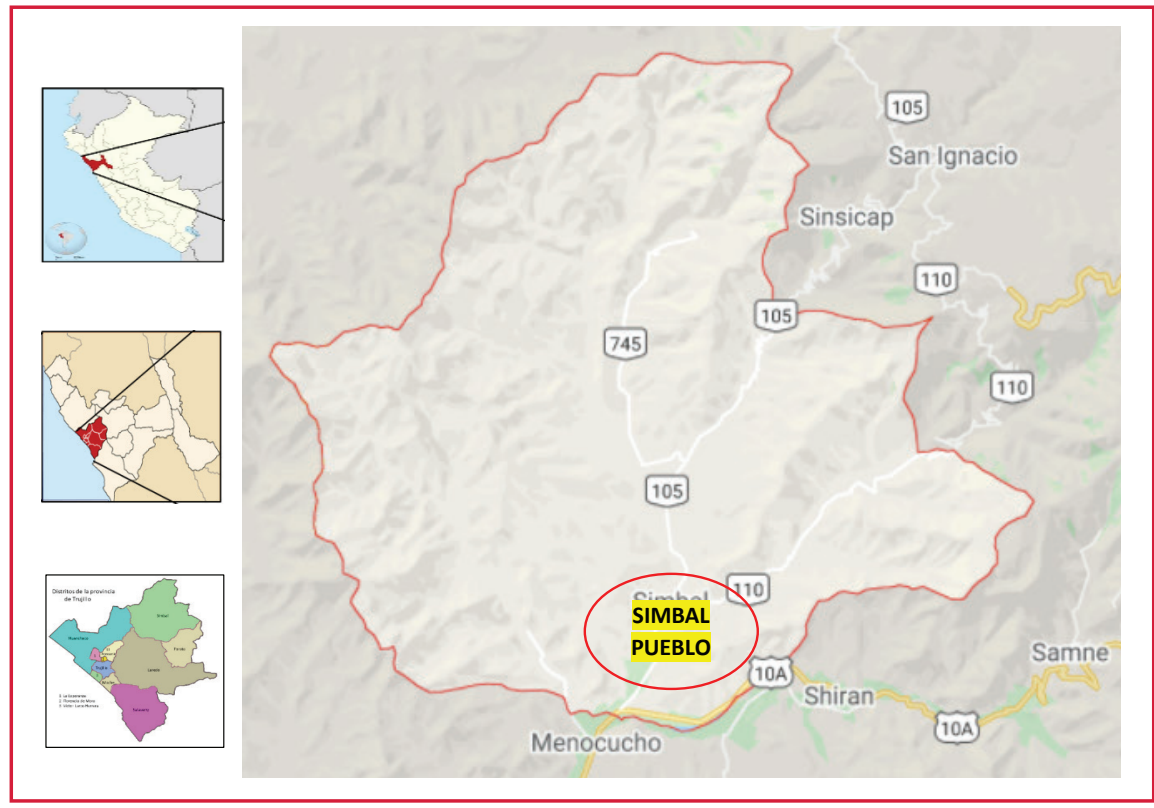

Figura 1. Ubicación del distrito de Simbal, La Libertad, Perú

\section{Muestra}

Compuesta por 93 habitantes del distrito de Simbal; que habían empleado la flora. Para obtener esta cifra se hizo uso de la siguiente fórmula, según Bocanegra et al. (2011).

$$
\mathrm{n}=\frac{\mathrm{N} Z^{2} p q}{d^{2}(N-1)+Z^{2} p q}
$$

Dónde, n: Tamaño de la muestra; N: Población del estudio: 4350 habitantes (INEI, 2018); p: Proporción de éxito de la característica de interés, igual a $50 \%(0.5) ;$ q: 1 - P = complemento de P; Z: Coeficiente de confiabilidad al $95 \%$ igual a 1.96; d: Tolerancia de error permisible en la investigación = 0.1 (10 \%).

$$
\mathrm{n}=\frac{(4350) 1.96^{2}(0.5)(0.5)}{0.1^{2}(4350-1)+1.96^{2}(0.5)(0.5)}=96
$$




\section{Validación y confiabilidad del instrumento}

La validación de la encuesta se hizo a través del asesor y en base a publicaciones anteriores realizadas por Alipio et al. (2020), De la Cruz \& Mostacero (2020) y Ramírez et al. (2020), de las cuales se ejecutaron los ajustes convenientes para lograr obtener la versión definitiva del instrumento.

\section{Criterio de inclusión y exclusión}

Personas mayores de 20 años, habitantes del distrito de Simbal y que hayan hecho uso de la flora, para satisfacer sus necesidades.

Personas que no respondan íntegramente la entrevista o muestren indicios de información falsa.

\section{Instrumento y técnica de recolección de datos}

Como instrumento se empleó la entrevista semiestructurada. Esta consistió en 2 secciones: la primera sección consideró la información propia del(la) encuestado y la siguiente sección, consideró los datos etnobotánicos compilados en las diferentes formas de uso (atrayente fauna silvestre, carnada, forraje, aceite, alimento de consumo directo, bebidas, masas y harinas, leña, navegación - transporte, construcción de viviendas, cordelería, implementos para caza y pesca, utensilios de uso doméstico y de trabajo, cura y/o alivio de enfermedades, embarazo, parto y puerperio, recreacional, lúdico, ritual, ropa y accesorios, cosmético, tintes y otros) de cada especie para suplir sus necesidades en los diferentes ámbitos de su vida (Alipio et al, 2020; De la Cruz y Mostacero, 2020).

Ahora bien, para la aplicación de las entrevistas, primero se definió el número de encuestas en Simbal pueblo (18) y en cada uno de sus caseríos, tomando en cuenta la proporción demográfica de cada uno de estos lugares; quedando de la siguiente manera: Mucha (5), Rasday (5), Pedregal (5), Cajamarca (5), Ñary (5), Cumbray (5), Chacchit (5), Chual (5), Catuay Alto (5), Cruz Blanca (5), La Constancia (5), Cerro Prieto (5), Cholocal (5), Collambay (5) y Huangabal (5).

Luego de ello se procedió aplicar las entrevistas, mediante la técnica de "bola de nieve", que considera como informantes a los moradores conocedores del uso de la flora (Bailey, 1994) procediéndose a ubicar al primer entrevistado en cada uno de los lugares, el cual nos brindó todo sus conocimientos sobre la flora que empleaba en su día a día, una vez culminada la entrevista, el informante sugirió el próximo poblador a encuestar, quien de la misma manera contribuyó en el acopio de datos del conocimiento etnobotánico y así se continuó con los informantes restantes, hasta culminar las 93 encuestas.

\section{Determinación de la flora medicinal}

Paralelamente a la aplicación de las entrevistas se realizó la colecta de los especímenes botánicos, en compañía de una de las personas conocedoras de la zona.

Cabe destacar que las plantas colectadas fueron determinados taxonómicamente por comparación con los registrados en el Herbarium Truxillense (H.U.T.).

También, se hizo uso de claves taxonómicas relacionadas con la vegetación propia del territorio peruano; agenciados continuamente de los libros Brako \& Zarucchi (1993) y Mostacero et al. (2009), así como de los portales virtuales: Trópicos y The Plant List.

\section{Análisis de datos}

Posteriormente a la determinación se procedió a organizar en tablas los datos siguientes: familia, nombre científico, nombre vulgar, hábitat, habito, parte de la planta usada, método de propagación, y los índices de identificación de las especies botánicas con mayor valor cultural, para lo cual se determinó el Índice de Importancia Cultural (IC) postulado por Tardío \& Pardo (2008).

$$
\text { ICe }=\sum_{\mathrm{u}=\mathrm{u} 1}^{\mathrm{uNC}} \sum_{\mathrm{i}=\mathrm{i} 1}^{\mathrm{iN}} \text { RUuie/N }
$$

Donde, IC: Índice cultural de la especie; RU: Reporte de uso de la especie; N: Cantidad de pobladores tomados en cuenta en la investigación.

Cabe destacar que, el IC varía de 0 (si la variedad no fue empleada de ninguna manera) hasta la 
cantidad de categorías de uso, las cuales se adaptaron de las planteadas por Paniagua et al. 2010 y Ramírez et al. 2020, siendo las 09 categorías de uso consideradas: Alimentación humana, Medicinal, Madereras, Uso cultural, Ornamentales, Utensilios y Herramientas, Combustibles y Otros.

Por último, se agregaron los gráficos correspondientes al análisis de las tablas y se procedió a redactar el informe final.

\section{Aspectos éticos}

Se tuvo el permiso expedido oralmente de los habitantes tomados en cuenta para la investigación, para poder procesar y analizar los datos brindados. De igual manera, se consideró su derecho a la privacidad en todo momento.

\section{RESULTADOS Y DISCUSIÓN}

Se presenta la taxonomía y etnobotánica de las especies: nombre científico, familia, nombre común o vulgar, hábito, hábitat, forma de propagación, la parte utilizada, el reporte de uso (RU) y el índice cultural (IC); de cada una de las 125 especies reconocidas por el poblador del distrito de Simbal en las diferentes categorías de uso (Tabla 1); diseminadas en 104 géneros y 45 familias, teniendo principalmente a: Leguminosae (Fabaceae) (14 especies), Solanaceae (11 especies), Compositae (Asteraceas) (8 especies), Poaceae (8 especies), quienes registraron el mayor número de especies reconocidas por el poblador del distrito de Simbal. Lo cual va acorde a lo reportado por La Torre \& Albán (2006), Mostacero et al. (2009), Mostacero et al. (2011), Barreno (2012), Rodríguez et al. (2016) y De La Cruz \& Mostacero (2020), quienes afirman la gran adaptabilidad de las especies de la familia de las leguminosas al poblar gran diversidad de hábitats, caracterizándose como una familia cosmopolita y añadiendo a ello su notable importancia en el ámbito cultural y alimenticio, donde fue consumida por su gran valor nutritivo y riqueza en proteínas, carbohidratos y fibras; por lo que resulta imprescindible revalorar estas especies utilizadas desde tiempos ancestrales para conservar el legado de nuestros antepasados y de esta manera construir una base de datos para futuras investigaciones que sean de beneficio para el poblador y población en general(Alipio et al, 2020; De La Cruz \& Mostacero, 2020).

De igual manera, en la Tabla 1, se vislumbra que las 125 especies reportadas por el poblador del distrito de Simbal, se encuentran enmarcadas en nueve categorías, de la siguiente manera: 9 especies en AA (Alimentación Animal), 75 especies en $\mathrm{AH}$ (Alimentación Humana), 37 especies en $M$ (Medicinal), 9 especies en MA (Madereras), 3 especies en UC (Usos culturales), 21 especies en OR (Ornamental), 5 especies en UH (Utensilios y Herramientas), 9 especies en C (Combustible) y 1 especie en $\mathrm{O}$ (Otros).

Cabe destacar que, según el índice Cultural (IC), se muestran como las especies de mayor importancia a: Zea mays L. maiz $(I C=1.49)$, Zingiber officinale Roscoe "kion" (IC=1.49), Allium sativum L. "ajo" (IC $=1.47)$, Melia azedarach L. "cinamomo" (IC = 1.43), Piper aduncum L. "matico" (IC = 1.35), Persea americana Mill. "palta" (IC = 1.19), Matricaria chamomilla L. "manzanilla" (IC = 1.05), Opuntia ficus-indica L. Mill. "tuna" (IC $=1.05)$, Rosmarinus officinalis L. "romero" (IC $=1.00)$ y Pinus patula Schiede ex Schltdl. \& Cham. "pino" (IC=0.98) (Tabla 1), datos que concuerdan con lo expuesto por Rodríguez et al. (2016), al destacar la importancia de estas especies dadas por el poblador del distrito de Simbal en los variados aspectos de su día a día; entre ellos Zea mays L. "maíz" se tiene como la especie más considerada en la localidad al constituir una de las principales actividades económicas como cultivo (Rodríguez, 2014), presentándose de esta manera como un cultivo provechoso, de alto valor nutritivo y elevado potencial; lo cual encaja acorde a lo propuesto por La Torre \& Albán (2006), Mostacero et al. (2009), Arias et al. (2018), Casas et al. (2019) y Ramírez et al. (2020), quienes colocan al "maíz" como uno de los cultivos más difundidos y con una amplia variedad a nivel mundial, destinándolo para una gran variedad de áreas como es la industrial donde se centra en la obtención y aprovechamiento de sus aceites, proteínas, almidón y fibra proveniente de los granos de estas especies, y en el área alimenticia posee gran importancia tanto como alimento de ganado como alimento humano en muchas de sus variedades, usándose también para la 
fabricación de bebidas.

Asimismo, se tiene en cuenta la presencia de especies como "kion", "ajo", "cinamomo", "matico", "palta", "manzanilla", "tuna", "romero", "pino", que son parte del conocimiento etnobotánico del poblador del distrito de Simbal.

Tabla 1

Caracteres taxonómicos y etnobotánicos de la flora empleada por el poblador del distrito de Simbal, Trujillo, La Libertad, Perú

\begin{tabular}{|c|c|c|c|c|c|c|c|c|c|}
\hline № & $\begin{array}{l}\text { NOMBRE CIENTÍFICO/ } \\
\text { FAMILIA }\end{array}$ & $\begin{array}{l}\text { NOMBRES } \\
\text { VULGARES Y/O } \\
\text { COMUNES }\end{array}$ & HABITO & HABITAT & F.P. & P. U. & C. U. & R. U. & I. C. \\
\hline 1 & $\begin{array}{c}\text { Acacia macracantha Willd. } \\
\text { (LEGUMINOSAE) }\end{array}$ & "espino" & $\begin{array}{l}\text { árbol de } \\
4 \text { metros }\end{array}$ & $\begin{array}{l}\text { terrenos húmedos } \\
\text { y laderas de los } \\
\text { cerros }\end{array}$ & $\begin{array}{l}\text { semillas y } \\
\text { esquejes }\end{array}$ & $\begin{array}{l}\text { flores, hojas } \\
\text { y frutos }\end{array}$ & OR, C & 43 & 0.46 \\
\hline 2 & $\begin{array}{l}\text { Allium ampeloprasum L. } \\
\text { (AMARYLLIDACEAE) }\end{array}$ & $\begin{array}{l}\text { "poro", } \\
\text { "puerro" }\end{array}$ & $\begin{array}{l}\text { hierba de } 50 \\
\text { centímetros }\end{array}$ & $\begin{array}{l}\text { terrenos húmedos } \\
\text { y cerca de las } \\
\text { acequias }\end{array}$ & semillas & hojas & $\mathrm{AH}$ & 42 & 0.45 \\
\hline 3 & $\begin{array}{c}\text { Allium cepa L. (AMARYL- } \\
\text { LIDACEAE) }\end{array}$ & "cebolla" & $\begin{array}{l}\text { hierba de } 50 \\
\text { centímetros }\end{array}$ & terrenos de cultivo & $\begin{array}{l}\text { semilla y } \\
\text { bulbos }\end{array}$ & bulbos & $\mathrm{AH}, \mathrm{M}$ & 87 & 0.93 \\
\hline 4 & $\begin{array}{l}\text { Allium sativum L. (AMA- } \\
\text { RYLLIDACEAE) }\end{array}$ & "ajo" & $\begin{array}{l}\text { hierba de } 30 \\
\text { centímetros }\end{array}$ & terrenos húmedos & $\begin{array}{l}\text { semilla y } \\
\text { bulbos }\end{array}$ & bulbos & $\mathrm{AH}, \mathrm{M}$ & 138 & 1.47 \\
\hline 5 & $\begin{array}{c}\text { Aloe vera (L.) Burm.f. } \\
\text { (XANTHORRHOEACEAE) }\end{array}$ & "sábila" & $\begin{array}{l}\text { hierba de } 30 \\
\text { centímetros }\end{array}$ & terrenos de cultivo & $\begin{array}{l}\text { semillas y } \\
\text { esquejes }\end{array}$ & hojas & $\mathrm{AH}, \mathrm{M}$ & 57 & 0.61 \\
\hline 6 & $\begin{array}{l}\text { Alternanthera halimifolia } \\
\text { (Lam.) Standl. ex Pittier } \\
\text { (AMARANTHACEAE) }\end{array}$ & $\begin{array}{l}\text { "hierba } \\
\text { blanca" }\end{array}$ & $\begin{array}{l}\text { hierba de } \\
1 \text { metro }\end{array}$ & $\begin{array}{l}\text { laderas de cerros } \\
\text { y alrededor de los } \\
\text { terrenos de cultivo }\end{array}$ & $\begin{array}{l}\text { semillas y } \\
\text { esquejes }\end{array}$ & $\begin{array}{l}\text { hojas y } \\
\text { flores }\end{array}$ & $\mathrm{AA}, \mathrm{M}$ & 53 & 0.56 \\
\hline 7 & $\begin{array}{l}\text { Amaranthus caudatus L. } \\
\text { (AMARANTHACEAE) }\end{array}$ & $\begin{array}{l}\text { "kiwicha", } \\
\text { "quihuicha" }\end{array}$ & $\begin{array}{l}\text { hierba de } 2 \\
\text { metros }\end{array}$ & $\begin{array}{l}\text { laderas de los } \\
\text { cerros y terrenos de } \\
\text { cultivo }\end{array}$ & semillas & granos & $\mathrm{AH}$ & 61 & 0.65 \\
\hline 8 & $\begin{array}{c}\text { Aniba puchury-minor } \\
\text { (Mart.) Mez (LAURACEAE) }\end{array}$ & "moena" & $\begin{array}{l}\text { árbol de } 20 \\
\text { metros }\end{array}$ & $\begin{array}{l}\text { laderas de los } \\
\text { cerros }\end{array}$ & $\begin{array}{l}\text { semillas y } \\
\text { esquejes }\end{array}$ & flores y tallo & MA & 11 & 0.12 \\
\hline 9 & $\begin{array}{l}\text { Annona cherimola Mill. } \\
\text { (ANNONACEAE) }\end{array}$ & "chirimoya" & $\begin{array}{l}\text { árbol de } \\
7 \text { metros }\end{array}$ & terrenos de cultivo & semillas & frutos & $\mathrm{AH}$ & 22 & 0.23 \\
\hline 10 & $\begin{array}{c}\text { Annona muricata L. (AN- } \\
\text { NONACEAE) }\end{array}$ & "guanábana" & $\begin{array}{l}\text { árbol de } \\
3 \text { metros }\end{array}$ & terrenos de cultivo & semillas & $\begin{array}{l}\text { frutos, hojas, } \\
\text { corteza y } \\
\text { raíz. }\end{array}$ & $\mathrm{AH}, \mathrm{M}$ & 91 & 0.97 \\
\hline 11 & $\begin{array}{l}\text { Anthurium andraeanum } \\
\text { Linden ex André } \\
\text { (ARACEAE) }\end{array}$ & "anturio" & $\begin{array}{l}\text { hierba de } 80 \\
\text { centímetros }\end{array}$ & $\begin{array}{l}\text { terrenos húmedos y } \\
\text { terrenos de cultivo }\end{array}$ & $\begin{array}{l}\text { semillas y } \\
\text { esquejes }\end{array}$ & $\begin{array}{l}\text { toda la } \\
\text { planta }\end{array}$ & OR & 23 & 0.24 \\
\hline 12 & $\begin{array}{l}\text { Apium graveolens L. } \\
\text { (APIACEAE) }\end{array}$ & "аріо" & $\begin{array}{l}\text { hierba de } 80 \\
\text { centímetros }\end{array}$ & terrenos de cultivo & semillas & tallos & $\mathrm{AH}$ & 42 & 0.45 \\
\hline 13 & $\begin{array}{c}\text { Arracacia xanthorrhiza } \\
\text { Bancr. (APIACEAE) }\end{array}$ & "arracacha" & $\begin{array}{l}\text { hierba de } \\
1 \text { metro }\end{array}$ & terrenos de cultivo & semillas & raíz & $\mathrm{AH}$ & 16 & 0.17 \\
\hline 14 & $\begin{array}{l}\text { Artemisia absinthium L. } \\
\text { (COMPOSITAE) }\end{array}$ & "ajenjo" & $\begin{array}{l}\text { hierba de } 80 \\
\text { centímetros }\end{array}$ & $\begin{array}{l}\text { terrenos secos y } \\
\text { terrenos de cultivo }\end{array}$ & $\begin{array}{l}\text { semillas y } \\
\text { esquejes }\end{array}$ & $\begin{array}{l}\text { hojas y } \\
\text { flores }\end{array}$ & M & 21 & 0.22 \\
\hline 15 & $\begin{array}{l}\text { Arundo donax L. } \\
\quad \text { (POACEAE) }\end{array}$ & "carrizo" & caña de 1 metro & $\begin{array}{l}\text { terrenos húmedos, } \\
\text { alrededor de las } \\
\text { acequias }\end{array}$ & $\begin{array}{l}\text { semillas y } \\
\text { estolones }\end{array}$ & tallos & $\begin{array}{l}\text { AA, MA, } \\
\text { UH }\end{array}$ & 87 & 0.93 \\
\hline 16 & $\begin{array}{l}\text { Asparagus officinalis L. } \\
\text { (ASPARAGACEAE) }\end{array}$ & "esparrago" & $\begin{array}{l}\text { hierba de } 1.8 \\
\text { metros }\end{array}$ & terrenos de cultivo & plántulas & tallo & $\mathrm{AH}$ & 24 & 0.26 \\
\hline 17 & $\begin{array}{l}\text { Bellis perennis L. } \\
\text { (COMPOSITAE) }\end{array}$ & "margarita" & $\begin{array}{l}\text { hierba de } 25 \\
\text { centímetros }\end{array}$ & $\begin{array}{l}\text { pastizales, laderas } \\
\text { de los cerros y } \\
\text { terrenos húmedos }\end{array}$ & semillas & $\begin{array}{l}\text { hojas, raíces } \\
\text { y flores }\end{array}$ & OR & 25 & 0.27 \\
\hline
\end{tabular}




\begin{tabular}{|c|c|c|c|c|c|c|c|c|c|}
\hline 18 & $\begin{array}{c}\text { Beta vulgaris L. } \\
\text { (AMARANTHACEAE) }\end{array}$ & "betarraga" & $\begin{array}{l}\text { hierba de } \\
1 \text { metro }\end{array}$ & terrenos de cultivo & semillas & raíz & $\mathrm{AH}$ & 42 & 0.45 \\
\hline 19 & $\begin{array}{l}\text { Bixa orellana L. } \\
\text { (BIXACEAE) }\end{array}$ & "achiote" & $\begin{array}{l}\text { árbol de } \\
2 \text { metros }\end{array}$ & $\begin{array}{l}\text { cerca de las ace- } \\
\text { quias y laderas de } \\
\text { los cerros }\end{array}$ & $\begin{array}{l}\text { semillas y } \\
\text { estacas }\end{array}$ & $\begin{array}{l}\text { hojas y } \\
\text { semillas }\end{array}$ & M & 27 & 0.29 \\
\hline 20 & $\begin{array}{l}\text { Brassica oleracea L. } \\
\text { (BRASSICACEAE) }\end{array}$ & "repollo" & $\begin{array}{l}\text { hierba de } 45 \\
\text { centímetros }\end{array}$ & terrenos de cultivo & semillas & hojas & $\mathrm{AH}$ & 22 & 0.23 \\
\hline 21 & $\begin{array}{l}\text { Brassica rapa } \mathrm{L} \text {. } \\
\text { (BRASSICACEAE) }\end{array}$ & "col" & $\begin{array}{l}\text { hierba de } 30 \\
\text { centímetros }\end{array}$ & terrenos de cultivo & semillas & hojas & $\mathrm{AH}$ & 17 & 0.18 \\
\hline 22 & $\begin{array}{c}\text { Caesalpinia spinosa } \\
\text { (Molina) } \\
\text { Kuntze (LEGUMINOSAE) }\end{array}$ & "taya", "tara" & $\begin{array}{l}\text { árbol de } \\
6 \text { metros }\end{array}$ & $\begin{array}{l}\text { terrenos de cultivo } \\
\text { y laderas de los } \\
\text { cerros }\end{array}$ & $\begin{array}{l}\text { semilla y } \\
\text { esquejes }\end{array}$ & $\begin{array}{l}\text { toda la } \\
\text { planta }\end{array}$ & M & 21 & 0.22 \\
\hline 23 & $\begin{array}{l}\text { Capsicum annuum L. } \\
\text { (SOLANACEAE) }\end{array}$ & "aji" & $\begin{array}{l}\text { hierba de } \\
1 \text { metro }\end{array}$ & terrenos de cultivo & semillas & fruto & $\mathrm{AH}$ & 38 & 0.4 \\
\hline 24 & $\begin{array}{l}\text { Cedrela odorata L. } \\
\text { (MELIACEAE) }\end{array}$ & "cedro" & $\begin{array}{l}\text { árbol de } 20 \\
\text { metros }\end{array}$ & $\begin{array}{l}\text { laderas de los } \\
\text { cerros }\end{array}$ & $\begin{array}{l}\text { semilla y } \\
\text { esquejes }\end{array}$ & $\begin{array}{l}\text { raíz, corteza } \\
\text { y tallo }\end{array}$ & MA & 43 & 0.46 \\
\hline 25 & $\begin{array}{c}\text { Cedrelinga cateniformis } \\
\text { (Ducke) } \\
\text { Ducke (LEGUMINOSAE) }\end{array}$ & "tornillo" & $\begin{array}{l}\text { árbol de } 30 \\
\text { metros }\end{array}$ & $\begin{array}{l}\text { laderas de los } \\
\text { cerros }\end{array}$ & $\begin{array}{l}\text { semilla y } \\
\text { esquejes }\end{array}$ & $\begin{array}{l}\text { raíz, corteza } \\
\text { y tallo }\end{array}$ & MA & 39 & 0.41 \\
\hline 26 & $\begin{array}{l}\text { Cestrum auriculatum } \\
\text { L'Hér. (SOLANACEAE) }\end{array}$ & "hierba santa" & $\begin{array}{l}\text { arbusto de } 2 \\
\text { metros }\end{array}$ & $\begin{array}{l}\text { cerca de las ace- } \\
\text { quias y terrenos de } \\
\text { cultivo }\end{array}$ & $\begin{array}{l}\text { semillas y } \\
\text { estacas }\end{array}$ & hojas & M & 13 & 0.14 \\
\hline 27 & $\begin{array}{l}\text { Chenopodium quinoa } \\
\text { Willd. } \\
\text { (AMARANTHACEAE) }\end{array}$ & $\begin{array}{l}\text { "quinua", } \\
\text { "quinoa" }\end{array}$ & $\begin{array}{l}\text { hierba de } 2 \\
\text { metros }\end{array}$ & $\begin{array}{l}\text { laderas de los } \\
\text { cerros y terrenos de } \\
\text { cultivo }\end{array}$ & semillas & granos & $\mathrm{AH}$ & 66 & 0.7 \\
\hline 28 & $\begin{array}{c}\text { Chrysanthemum indicum } \\
\text { L. (COMPOSITAE) }\end{array}$ & $\begin{array}{l}\text { "pompones", } \\
\text { "crisantemos" }\end{array}$ & $\begin{array}{l}\text { hierba de } 30 \\
\text { centímetros }\end{array}$ & $\begin{array}{l}\text { laderas de cerros y } \\
\text { terrenos de cultivos }\end{array}$ & $\begin{array}{l}\text { semillas y } \\
\text { esquejes }\end{array}$ & $\begin{array}{l}\text { flores y } \\
\text { hojas }\end{array}$ & OR & 16 & 0.16 \\
\hline 29 & $\begin{array}{l}\text { Cicer arietinum L. } \\
\text { (LEGUMINOSAE) }\end{array}$ & "garbanzo" & $\begin{array}{l}\text { hierba de } 60 \\
\text { centímetros }\end{array}$ & $\begin{array}{l}\text { terrenos arcillosos } \\
\text { y terrenos de cultivo }\end{array}$ & semillas & semillas & $\mathrm{AH}$ & 46 & 0.49 \\
\hline 30 & $\begin{array}{l}\text { Citrullus lanatus (Thunb.) } \\
\text { Matsum. \& Nakai } \\
\text { (CUCURBITACEAE) }\end{array}$ & "sandia" & $\begin{array}{l}\text { hierba de } 50 \\
\text { centímetros }\end{array}$ & terrenos de cultivo & semillas & frutos & $\mathrm{AH}$ & 41 & 0.44 \\
\hline 31 & $\begin{array}{l}\text { Citrus aurantiifolia } \\
\text { (Christm.) Swingle } \\
\text { (RUTACEAE) }\end{array}$ & "lima" & $\begin{array}{l}\text { árbol de } \\
6 \text { metros }\end{array}$ & terrenos de cultivo & semillas & frutos & $\mathrm{AH}$ & 21 & 0.22 \\
\hline 32 & $\begin{array}{l}\text { Citrus limon (L.) Burm. f. } \\
\text { (RUTACEAE) }\end{array}$ & "limón" & $\begin{array}{l}\text { árbol de } \\
5 \text { metros }\end{array}$ & $\begin{array}{l}\text { laderas de los } \\
\text { cerros y terrenos de } \\
\text { cultivo }\end{array}$ & semillas & frutos & $\mathrm{AH}$ & 65 & 0.69 \\
\hline 33 & $\begin{array}{l}\text { Citrus paradisi Macfad. } \\
\text { (RUTACEAE) }\end{array}$ & "toronja" & $\begin{array}{l}\text { árbol de } \\
5 \text { metros }\end{array}$ & terrenos de cultivo & semillas & frutos & $\mathrm{AH}$ & 16 & 0.17 \\
\hline 34 & $\begin{array}{l}\text { Citrus reticulata Blanco } \\
\text { (RUTACEAE) }\end{array}$ & "mandarina" & $\begin{array}{l}\text { árbol de } \\
6 \text { metros }\end{array}$ & terrenos de cultivo & semillas & frutos & $\mathrm{AH}$ & 34 & 0.36 \\
\hline 35 & $\begin{array}{c}\text { Citrus sinensis (L.) Osbeck } \\
\text { (RUTACEAE) }\end{array}$ & "naranja" & $\begin{array}{l}\text { árbol de } \\
8 \text { metros }\end{array}$ & $\begin{array}{l}\text { terrenos de cultivo y } \\
\text { terrenos húmedos }\end{array}$ & semillas & frutos & $\mathrm{AH}$ & 58 & 0.62 \\
\hline 36 & $\begin{array}{l}\text { Clinopodium pulchellum } \\
\text { (Kunth) Govaerts } \\
\text { (LAMIACEAE) }\end{array}$ & "panisara" & $\begin{array}{l}\text { hierba de } 20 \\
\text { centímetros }\end{array}$ & terrenos de cultivo & $\begin{array}{l}\text { semillas y } \\
\text { estolones }\end{array}$ & $\begin{array}{l}\text { hojas y } \\
\text { flores }\end{array}$ & $A H(B), M$ & 69 & 0.73 \\
\hline 37 & $\begin{array}{l}\text { Cordia lutea Lam. } \\
\text { (BORAGINACEAE) }\end{array}$ & "flor de overo" & $\begin{array}{l}\text { arbusto de } 8 \\
\text { metros }\end{array}$ & $\begin{array}{l}\text { terrenos de cultivo } \\
\text { y laderas de los } \\
\text { cerros }\end{array}$ & semillas & $\begin{array}{l}\text { hojas y } \\
\text { flores }\end{array}$ & M & 49 & 0.52 \\
\hline 38 & $\begin{array}{l}\text { Coriandrum sativum L. } \\
\text { (APIACEAE) }\end{array}$ & "culantro" & $\begin{array}{l}\text { hierba de } 60 \\
\text { centímetros }\end{array}$ & terrenos de cultivo & semillas & hojas & $\mathrm{AH}$ & 51 & 0.54 \\
\hline 39 & $\begin{array}{l}\text { Cucumis sativus L. } \\
\text { (CUCURBITACEAE) }\end{array}$ & "pepinillo" & hierba trepadora & terrenos de cultivo & semillas & fruto & $\mathrm{AH}$ & 59 & 0.63 \\
\hline
\end{tabular}




\begin{tabular}{|c|c|c|c|c|c|c|c|c|c|}
\hline 40 & $\begin{array}{c}\text { Cyclanthera pedata (L.) } \\
\text { Schrad. } \\
\text { (CUCURBITACEAE) }\end{array}$ & $\begin{array}{l}\text { "caigua", } \\
\text { "caihua" }\end{array}$ & $\begin{array}{l}\text { hierba de } 12 \\
\text { metros }\end{array}$ & terrenos de cultivo & semillas & frutos & $\mathrm{AH}$ & 31 & 0.33 \\
\hline 41 & $\begin{array}{c}\text { Cymbopogon citratus (DC.) } \\
\text { Stapf (POACEAE) }\end{array}$ & "hierba luisa" & $\begin{array}{l}\text { hierba de } 30 \\
\text { centímetros }\end{array}$ & $\begin{array}{l}\text { terrenos húmedos, } \\
\quad \text { pastizales y } \\
\text { terrenos de cultivo }\end{array}$ & $\begin{array}{l}\text { estacas y } \\
\text { acodos }\end{array}$ & hojas & $\mathrm{AH}(\mathrm{B}), \mathrm{M}$ & 77 & 0.82 \\
\hline 42 & $\begin{array}{l}\text { Cynodon dactylon (L.) } \\
\text { Pers. (POACEAE) }\end{array}$ & "gras" & $\begin{array}{l}\text { hierba de } 30 \\
\text { centímetros }\end{array}$ & $\begin{array}{l}\text { Ladera de los cerros } \\
\text { y matorrales }\end{array}$ & $\begin{array}{l}\text { semillas y } \\
\text { estolones }\end{array}$ & hojas & OR & 20 & 0.21 \\
\hline 43 & $\begin{array}{l}\text { Daucus carota } \mathrm{L} \text {. } \\
\text { (APIACEAE) }\end{array}$ & "zanahoria" & $\begin{array}{l}\text { hierba de } 40 \\
\text { centímetros }\end{array}$ & terrenos de cultivo & semillas & raíz & $\mathrm{AH}$ & 58 & 0.62 \\
\hline 44 & $\begin{array}{l}\text { Delonix regia (Hook.) Raf. } \\
\text { (LEGUMINOSAE) }\end{array}$ & "ponciana" & $\begin{array}{l}\text { árbol de } 15 \\
\text { metros }\end{array}$ & $\begin{array}{l}\text { alrededor de los } \\
\text { caminos }\end{array}$ & $\begin{array}{l}\text { semillas y } \\
\text { esquejes }\end{array}$ & $\begin{array}{l}\text { hojas, flores, } \\
\text { semillas y } \\
\text { raíz }\end{array}$ & OR & 46 & 0.49 \\
\hline 45 & $\begin{array}{l}\text { Dianthus caryophyllus L. } \\
\text { (CARYOPHYLLACEAE) }\end{array}$ & "clavel" & $\begin{array}{l}\text { hierba de } 60 \\
\text { centímetros }\end{array}$ & $\begin{array}{l}\text { laderas de los } \\
\text { cerros y tierras de } \\
\text { cultivo }\end{array}$ & $\begin{array}{l}\text { semillas y } \\
\text { esquejes }\end{array}$ & $\begin{array}{l}\text { hojas y } \\
\text { flores }\end{array}$ & OR & 21 & 0.22 \\
\hline 46 & $\begin{array}{l}\text { Echeveria elegans Rose } \\
\text { (CRASSULACEAE) }\end{array}$ & $\begin{array}{l}\text { "suculenta", } \\
\text { "rosa de } \\
\text { alabastro" }\end{array}$ & $\begin{array}{l}\text { hierba de } 25 \\
\text { centímetros }\end{array}$ & $\begin{array}{l}\text { matorrales y } \\
\text { terrenos secos }\end{array}$ & $\begin{array}{l}\text { semillas y } \\
\text { esquejes }\end{array}$ & hojas & OR & 9 & 0.10 \\
\hline 47 & $\begin{array}{l}\text { Equisetum arvense } \mathrm{L} \text {. } \\
\text { (EQUISETACEAE) }\end{array}$ & $\begin{array}{l}\text { "cola de } \\
\text { caballo" }\end{array}$ & $\begin{array}{l}\text { hierba de } 60 \\
\text { centímetros }\end{array}$ & terrenos húmedos & rizomas & hojas y tallo & M & 23 & 0.24 \\
\hline 48 & $\begin{array}{l}\text { Erythroxylum coca Lam. } \\
\text { (ERYTHROXYLACEAE) }\end{array}$ & "coca" & $\begin{array}{l}\text { arbusto de } 2,5 \\
\text { metros }\end{array}$ & terrenos húmedos & $\begin{array}{l}\text { semillas y } \\
\text { estacas }\end{array}$ & hojas & M & 19 & 0.20 \\
\hline 49 & $\begin{array}{l}\text { Espostoa lanata (Kunth) } \\
\text { Britton \& Rose } \\
\text { (CACTACEAE) }\end{array}$ & "lana vegetal" & $\begin{array}{l}\text { árbol de } \\
2 \text { metros }\end{array}$ & $\begin{array}{l}\text { terrenos secos } \\
\text { y laderas de los } \\
\text { cerros }\end{array}$ & $\begin{array}{l}\text { semillas y } \\
\text { esquejes }\end{array}$ & flores y tallo & OR & 58 & 0.62 \\
\hline 50 & $\begin{array}{c}\text { Eucalyptus globulus Labill. } \\
\text { (MYRTACEAE) }\end{array}$ & "eucalipto" & $\begin{array}{l}\text { árbol de } \\
15 \text { metros }\end{array}$ & terrenos húmedos & $\begin{array}{l}\text { semillas y } \\
\text { estacas }\end{array}$ & $\begin{array}{l}\text { hojas y } \\
\text { flores }\end{array}$ & $M, \cup C$ & 62 & 0.66 \\
\hline 51 & $\begin{array}{l}\text { Euphorbia pulcherrima } \\
\text { Willd. ex Klotzsch } \\
\text { (EUPHORBIACEAE) }\end{array}$ & $\begin{array}{l}\text { "cardenal", } \\
\text { "flor de } \\
\text { nochebuena" }\end{array}$ & $\begin{array}{l}\text { arbusto de } \\
4 \text { metros }\end{array}$ & $\begin{array}{l}\text { orillas de los cami- } \\
\text { nos y laderas de los } \\
\text { cerros }\end{array}$ & $\begin{array}{l}\text { semillas y } \\
\text { esquejes }\end{array}$ & flores & OR & 24 & 0.26 \\
\hline 52 & $\begin{array}{l}\text { Ficus insipida Willd. } \\
\text { (MORACEAE) }\end{array}$ & "ficus" & $\begin{array}{l}\text { árbol de } \\
10 \text { metros }\end{array}$ & $\begin{array}{l}\text { alrededor de los } \\
\text { caminos y laderas } \\
\text { de los cerros }\end{array}$ & $\begin{array}{l}\text { semillas, } \\
\text { esquejes }\end{array}$ & $\begin{array}{l}\text { toda la } \\
\text { planta }\end{array}$ & OR & 55 & 0.59 \\
\hline 53 & $\begin{array}{l}\text { Fragaria vesca } \mathrm{L} \text {. } \\
\quad(\mathrm{ROSACEAE})\end{array}$ & "fresa" & hierba postrada & terrenos de cultivo & semillas & frutos & $\mathrm{AH}$ & 51 & 0.54 \\
\hline 54 & $\begin{array}{c}\text { Afuchsia magellanica Lam. } \\
\text { (ONAGRACEAE) }\end{array}$ & $\begin{array}{l}\text { "chilco", } \\
\text { "thilco" }\end{array}$ & $\begin{array}{l}\text { arbusto de } \\
3 \text { metros }\end{array}$ & $\begin{array}{c}\text { cerca de las } \\
\text { acequias y terrenos } \\
\text { húmedos }\end{array}$ & $\begin{array}{l}\text { semillas y } \\
\text { estacas }\end{array}$ & $\begin{array}{l}\text { flores y } \\
\text { hojas }\end{array}$ & C & 11 & 0.12 \\
\hline 55 & $\begin{array}{c}\text { Gynerium sagittatum } \\
\text { (Aubl.) P.Beauv. } \\
\text { (POACEAE) }\end{array}$ & "caña brava" & $\begin{array}{l}\text { caña de } \\
3 \text { metros }\end{array}$ & $\begin{array}{l}\text { cerca de las } \\
\text { acequias }\end{array}$ & $\begin{array}{l}\text { semillas y } \\
\text { estolone }\end{array}$ & $\begin{array}{l}\text { hojas, tallos } \\
\text { y raíz }\end{array}$ & MA, UH & 81 & 0.86 \\
\hline 56 & $\begin{array}{l}\text { Helianthus annuus L. } \\
\text { (COMPOSITAE) }\end{array}$ & "girasol" & $\begin{array}{l}\text { hierba de } \\
3 \text { metros }\end{array}$ & $\begin{array}{l}\text { terrenos de cultivo } \\
\text { y laderas de los } \\
\text { cerro }\end{array}$ & semillas & $\begin{array}{l}\text { flores, semi- } \\
\text { llas, hojas y } \\
\quad \text { tallo }\end{array}$ & $\mathrm{AH}, \mathrm{OR}$ & 73 & 0.78 \\
\hline 57 & $\begin{array}{l}\text { Inga feuilleei DC. } \\
\text { (LEGUMINOSAE) }\end{array}$ & "guaba" & $\begin{array}{l}\text { árbol de } \\
8 \text { metros }\end{array}$ & $\begin{array}{l}\text { terrenos de cultivo y } \\
\text { terrenos húmedos }\end{array}$ & semillas & $\begin{array}{l}\text { tronco, } \\
\text { frutos y } \\
\text { hojas }\end{array}$ & $\mathrm{AA}, \mathrm{AH}, \mathrm{C}$ & 44 & 0.77 \\
\hline 58 & $\begin{array}{l}\text { Ipomoea batatas (L.) Poir. } \\
\text { (CONVOLVULACEAE) }\end{array}$ & "camote" & $\begin{array}{l}\text { hierba de } \\
1 \text { metro }\end{array}$ & $\begin{array}{l}\text { terrenos húmedos y } \\
\text { terrenos de cultivo }\end{array}$ & esquejes & hojas, raíz & $\mathrm{AA}, \mathrm{AH}$ & 60 & 0.64 \\
\hline 59 & $\begin{array}{c}\text { Lablab purpureus (L.) } \\
\text { Sweet } \\
\text { (LEGUMINOSAE) }\end{array}$ & "zarandaja" & $\begin{array}{l}\text { hierba de } \\
6 \text { metros }\end{array}$ & $\begin{array}{l}\text { terrenos húmedos y } \\
\text { terrenos de cultivo }\end{array}$ & semillas & semillas & $\mathrm{AH}$ & 41 & 0.44 \\
\hline 60 & $\begin{array}{l}\text { Lactuca sativa L. } \\
\text { (COMPOSITAE) }\end{array}$ & "lechuga" & $\begin{array}{l}\text { hierba de } 25 \\
\text { centímetros }\end{array}$ & terrenos de cultivo & semillas & hojas y tallo & $\mathrm{AH}, \mathrm{M}$ & 41 & 0.44 \\
\hline 61 & $\begin{array}{l}\text { Lens culinaris Medik } \\
\text { (LEGUMINOSAE) }\end{array}$ & "lenteja" & $\begin{array}{l}\text { hierba de } 40 \\
\text { centímetros }\end{array}$ & $\begin{array}{l}\text { pedregales y ter- } \\
\text { renos de cultivo }\end{array}$ & semillas & semillas & $\mathrm{AH}$ & 76 & 0.81 \\
\hline
\end{tabular}




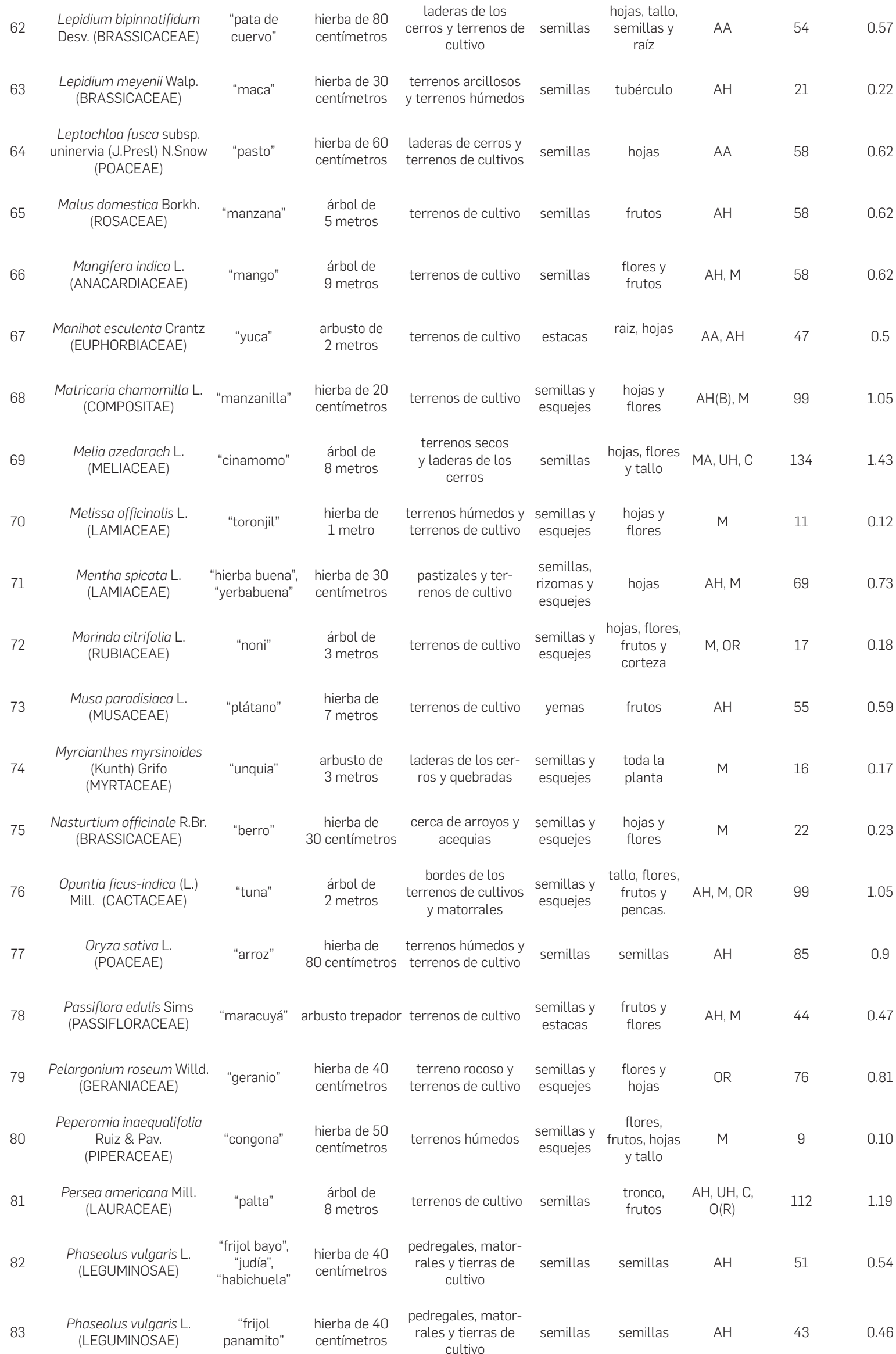

\section{1}




\begin{tabular}{|c|c|c|c|c|c|c|c|c|c|}
\hline 84 & $\begin{array}{l}\text { Phaseolus vulgaris L. } \\
\text { (LEGUMINOSAE) }\end{array}$ & $\begin{array}{c}\text { "frejol } \\
\text { caballero" }\end{array}$ & $\begin{array}{l}\text { hierba de } \\
40 \text { centímetros }\end{array}$ & $\begin{array}{l}\text { pedregales, mator- } \\
\text { rales y tierras de } \\
\text { cultivo }\end{array}$ & semillas & semillas & $\mathrm{AH}$ & 21 & 0.22 \\
\hline 85 & $\begin{array}{l}\text { Phaseolus vulgaris L. } \\
\text { (LEGUMINOSAE) }\end{array}$ & $\begin{array}{l}\text { "frejol ojo } \\
\text { negro" }\end{array}$ & $\begin{array}{c}\text { hierba de } \\
40 \text { centímetros }\end{array}$ & $\begin{array}{l}\text { pedregales, ma- } \\
\text { torrales y tierras de } \\
\text { cultivo }\end{array}$ & semillas & semillas & $\mathrm{AH}$ & 17 & 0.18 \\
\hline 86 & $\begin{array}{l}\text { Phoenix dactylifera L. } \\
\text { (ARECACEAE) }\end{array}$ & "palmera" & $\begin{array}{l}\text { árbol de } \\
20 \text { metros }\end{array}$ & terrenos de cultivo & $\begin{array}{l}\text { semillas e } \\
\text { hijuelos }\end{array}$ & $\begin{array}{l}\text { toda la } \\
\text { planta }\end{array}$ & $\mathrm{AH}, \mathrm{OR}$ & 83 & 0.88 \\
\hline 87 & $\begin{array}{l}\text { Physalis peruviana } \mathrm{L} \text {. } \\
\text { (SOLANACEAE) }\end{array}$ & "aguaymanto" & $\begin{array}{l}\text { hierba de } \\
1 \text { metro }\end{array}$ & $\begin{array}{l}\text { terrenos húmedos y } \\
\text { terrenos de cultivo }\end{array}$ & semillas & frutos & $\mathrm{AH}$ & 33 & 0.35 \\
\hline 88 & $\begin{array}{l}\text { Pimpinella anisum L. } \\
\text { (APIACEAE) }\end{array}$ & "anís" & $\begin{array}{l}\text { hierba de } \\
1 \text { metro }\end{array}$ & terrenos de cultivo & semillas & $\begin{array}{l}\text { toda la } \\
\text { planta }\end{array}$ & $\mathrm{AH}(\mathrm{B}), \mathrm{M}$ & 52 & 0.55 \\
\hline 89 & $\begin{array}{l}\text { Pinus patula Schiede ex } \\
\text { Schltdl. \& Cham. } \\
\text { (PINACEAE) }\end{array}$ & "pino" & $\begin{array}{l}\text { árbol de } \\
20 \text { metros }\end{array}$ & $\begin{array}{l}\text { laderas de los } \\
\text { cerros }\end{array}$ & $\begin{array}{l}\text { semillas y } \\
\text { esquejes }\end{array}$ & $\begin{array}{l}\text { raíz, corteza } \\
\text { y tallo }\end{array}$ & $\mathrm{MA}, \mathrm{OR}, \mathrm{C}$ & 92 & 0.98 \\
\hline 90 & $\begin{array}{c}\text { Piper aduncum L. } \\
\text { (Piperaceae) }\end{array}$ & "matico" & $\begin{array}{l}\text { árbol de } \\
7 \text { metros }\end{array}$ & $\begin{array}{l}\text { terrenos secos, } \\
\text { laderas de los cer- } \\
\text { ros y quebradas }\end{array}$ & $\begin{array}{l}\text { semillas y } \\
\text { esquejes }\end{array}$ & hojas & $\mathrm{AH}(\mathrm{B}), \mathrm{M}$ & 127 & 1.35 \\
\hline 91 & $\begin{array}{l}\text { Pisum sativum L. } \\
\text { (LEGUMINOSAE) }\end{array}$ & $\begin{array}{l}\text { "arveja", } \\
\text { "guisante" }\end{array}$ & $\begin{array}{l}\text { hierba de } 50 \\
\text { centímetros }\end{array}$ & terrenos de cultivo & semillas & semillas & $\mathrm{AH}$ & 67 & 0.71 \\
\hline 92 & $\begin{array}{l}\text { Plantago major } \mathrm{L} . \\
\text { (PLANTAGINACEAE) }\end{array}$ & "Ulantén" & $\begin{array}{l}\text { hierba de } 40 \\
\text { centímetros }\end{array}$ & $\begin{array}{l}\text { terrenos húmedos, } \\
\text { pastizales, tierras de } \\
\text { cultivo, alrededor de } \\
\text { los caminos }\end{array}$ & semillas & $\begin{array}{l}\text { hojas y } \\
\text { semillas }\end{array}$ & M & 63 & 0.67 \\
\hline 93 & $\begin{array}{l}\text { Plectranthus verticillatus " } \\
\text { (L.f.) Druce (LAMIACEAE) }\end{array}$ & $\begin{array}{l}\text { "dólar", "planta } \\
\text { del dinero" }\end{array}$ & $\begin{array}{l}\text { hierba de } 50 \\
\text { centímetros }\end{array}$ & $\begin{array}{l}\text { laderas de los } \\
\text { cerros y alrededor } \\
\text { de los caminos }\end{array}$ & $\begin{array}{l}\text { semillas y } \\
\text { esquejes }\end{array}$ & $\begin{array}{l}\text { hojas y } \\
\text { flores }\end{array}$ & OR & 34 & 0.36 \\
\hline 94 & $\begin{array}{l}\text { Portulaca oleracea L. } \\
\text { (PORTULACACEAE) }\end{array}$ & "verdolaga" & $\begin{array}{l}\text { hierba de } 40 \\
\text { centímetros }\end{array}$ & terrenos de cultivo & $\begin{array}{l}\text { semillas y } \\
\text { esquejes }\end{array}$ & $\begin{array}{l}\text { toda la } \\
\text { planta }\end{array}$ & AA & 46 & 0.49 \\
\hline 95 & $\begin{array}{c}\text { Pouteria lucuma (Ruiz \& } \\
\text { Pav.) Kuntze } \\
\text { (SAPOTACEAE) }\end{array}$ & "lúcuma" & $\begin{array}{l}\text { árbol de } \\
15 \text { metros }\end{array}$ & terrenos de cultivo & semillas & frutos & $\mathrm{AH}$ & 49 & 0.52 \\
\hline 96 & $\begin{array}{l}\text { Prosopis pallida (Willd.) } \\
\text { Kunth (LEGUMINOSAE) }\end{array}$ & "algarrobo" & $\begin{array}{l}\text { árbol de } \\
10 \text { metros }\end{array}$ & $\begin{array}{l}\text { terrenos secos } \\
\text { y laderas de los } \\
\text { cerros }\end{array}$ & $\begin{array}{l}\text { semilla y } \\
\text { esquejes }\end{array}$ & $\begin{array}{l}\text { frutos y } \\
\text { vaina }\end{array}$ & $\mathrm{UH}, \mathrm{C}$ & 61 & 0.65 \\
\hline 97 & $\begin{array}{l}\text { Prunus persica (L.) Batsch } \\
\text { (ROSACEAE) }\end{array}$ & "melocotón" & $\begin{array}{l}\text { árbol de } \\
45 \text { metros }\end{array}$ & terrenos de cultivo & semilla & fruto & $\mathrm{AH}$ & 47 & 0.5 \\
\hline 98 & $\begin{array}{l}\text { Psidium guajava L. } \\
\text { (MYRTACEAE) }\end{array}$ & "guayaba" & $\begin{array}{l}\text { árbol de } \\
3 \text { metros }\end{array}$ & terrenos de cultivo & semillas & frutos & $\mathrm{AH}$ & 22 & 0.23 \\
\hline 99 & $\begin{array}{l}\text { Raphanus raphanistrum } \\
\text { subsp. sativus (L.) Domin. } \\
\text { (BRASSICACEAE) }\end{array}$ & "rabanito" & $\begin{array}{l}\text { hierba de } 20 \\
\text { centímetros }\end{array}$ & $\begin{array}{l}\text { terrenos arcillosos } \\
\text { y terrenos de cultivo }\end{array}$ & semillas & raíz & $\mathrm{AH}$ & 68 & 0.72 \\
\hline 100 & $\begin{array}{l}\text { Rosa canina } \mathrm{L} \text {. } \\
\text { (ROSACEAE) }\end{array}$ & "rosa" & $\begin{array}{l}\text { arbusto de } \\
2 \text { metros }\end{array}$ & terrenos de cultivo & $\begin{array}{l}\text { semillas y } \\
\text { esqueje }\end{array}$ & $\begin{array}{l}\text { flores y } \\
\text { hojas }\end{array}$ & OR & 71 & 0.76 \\
\hline 101 & $\begin{array}{l}\text { Rosmarinus officinalis L. } \\
\quad \text { (LAMIACEAE) }\end{array}$ & "romero" & $\begin{array}{l}\text { arbusto de } \\
2 \text { metros }\end{array}$ & $\begin{array}{l}\text { alrededor de los } \\
\text { terrenos de cultivo }\end{array}$ & $\begin{array}{l}\text { semillas y } \\
\text { esquejes }\end{array}$ & $\begin{array}{l}\text { hojas y } \\
\text { flores }\end{array}$ & $\begin{array}{l}A H(B), M \\
U C\end{array}$ & 94 & 1.00 \\
\hline 102 & $\begin{array}{l}\text { Ruta graveolens L. } \\
\text { (RUTACEAE) }\end{array}$ & "ruda" & $\begin{array}{c}\text { arbusto de } \\
80 \text { centímetros }\end{array}$ & terrenos secos & $\begin{array}{l}\text { semillas y } \\
\text { esquejes }\end{array}$ & $\begin{array}{l}\text { hojas y } \\
\text { flores }\end{array}$ & $M, \cup C$ & 40 & 0.43 \\
\hline 103 & $\begin{array}{l}\text { Sapindus saponaria L. } \\
\quad \text { (SAPINDACEAE) }\end{array}$ & $\begin{array}{l}\text { "chano", } \\
\text { "choloque" }\end{array}$ & $\begin{array}{l}\text { árbol de } \\
12 \text { metros }\end{array}$ & $\begin{array}{l}\text { pastizales y ter- } \\
\text { renos secos }\end{array}$ & $\begin{array}{l}\text { semillas y } \\
\text { estacas }\end{array}$ & $\begin{array}{l}\text { toda la } \\
\text { planta }\end{array}$ & C & 25 & 0.27 \\
\hline 104 & $\begin{array}{l}\text { Schinus molle L. } \\
\text { (ANACARDIACEAE) }\end{array}$ & "molle" & $\begin{array}{l}\text { árbol de } \\
10 \text { metros }\end{array}$ & $\begin{array}{l}\text { laderas de los } \\
\text { cerros y alrededor } \\
\text { de las acequias }\end{array}$ & semillas & $\begin{array}{l}\text { semillas, } \\
\text { hojas, frutos } \\
\text { y corteza }\end{array}$ & $\mathrm{M}, \mathrm{MA}, \mathrm{OR}$ & 76 & 0.81 \\
\hline 105 & $\begin{array}{l}\text { Sebastiania obtusifolia Pax } \\
\text { \& K.Hoffm. } \\
\text { (EUPHORBIACEAE) }\end{array}$ & "planquillo", & $\begin{array}{l}\text { árbol de } \\
9 \text { metros }\end{array}$ & $\begin{array}{l}\text { laderas de los } \\
\text { cerros }\end{array}$ & $\begin{array}{l}\text { semillas y } \\
\text { esquejes }\end{array}$ & $\begin{array}{l}\text { toda la } \\
\text { planta }\end{array}$ & C & 31 & 0.33 \\
\hline
\end{tabular}




\begin{tabular}{|c|c|c|c|c|c|c|c|c|c|}
\hline 106 & $\begin{array}{l}\text { Solanum americanum Mill. } \\
\text { (SOLANACEAE) }\end{array}$ & $\begin{array}{c}\text { " "hierba de } \\
\text { mora" }\end{array}$ & $\begin{array}{l}\text { hierba de } \\
1 \text { metro }\end{array}$ & $\begin{array}{l}\text { bordes de caminos } \\
\text { y alrededor de los } \\
\text { terrenos de cultivo }\end{array}$ & semillas & $\begin{array}{l}\text { hojas, frutos } \\
\text { y flores }\end{array}$ & M & 2 & 0.02 \\
\hline 107 & $\begin{array}{l}\text { Solanum lycopersicum } \\
\text { Lam. (SOLANACEAE) }\end{array}$ & "tomate" & $\begin{array}{l}\text { hierba de } \\
2 \text { metros }\end{array}$ & terrenos arcillosos & $\begin{array}{l}\text { semillas, } \\
\text { esquejes }\end{array}$ & frutos & $\mathrm{AH}$ & 68 & 0.72 \\
\hline 108 & $\begin{array}{l}\text { Solanum muricatum Aiton } \\
\text { (SOLANACEAE) }\end{array}$ & "pepino" & $\begin{array}{l}\text { hierba de } \\
2 \text { metros }\end{array}$ & terrenos de cultivo & $\begin{array}{l}\text { semillas, } \\
\text { esquejes }\end{array}$ & fruto & $\mathrm{AH}$ & 41 & 0.44 \\
\hline 109 & $\begin{array}{l}\text { Solanum tuberosum L. } \\
\text { (SOLANACEAE) }\end{array}$ & $\begin{array}{c}\text { "papa } \\
\text { amarilla" }\end{array}$ & $\begin{array}{l}\text { hierba de } \\
1 \text { metro }\end{array}$ & terrenos de cultivo & $\begin{array}{l}\text { semillas y } \\
\text { esquejes }\end{array}$ & tubérculo & $\mathrm{AH}$ & 77 & 0.82 \\
\hline 110 & $\begin{array}{l}\text { Solanum tuberosum L. } \\
\text { (SOLANACEAE) }\end{array}$ & $\begin{array}{l}\text { "papa huevo } \\
\text { de indio" }\end{array}$ & $\begin{array}{l}\text { hierba de } \\
1 \text { metro }\end{array}$ & terrenos de cultivo & $\begin{array}{l}\text { semillas y } \\
\text { esquejes }\end{array}$ & tubérculo & $\mathrm{AH}$ & 42 & 0.45 \\
\hline 111 & $\begin{array}{l}\text { Solanum tuberosum L. } \\
\text { (SOLANACEAE) }\end{array}$ & "papa yungay" & $\begin{array}{l}\text { hierba de } \\
1 \text { metro }\end{array}$ & terrenos de cultivo & $\begin{array}{l}\text { semillas y } \\
\text { esquejes }\end{array}$ & tubérculo & $\mathrm{AH}$ & 73 & 0.78 \\
\hline 112 & $\begin{array}{l}\text { Solanum tuberosum L. } \\
\text { (SOLANACEAE) }\end{array}$ & $\begin{array}{c}\text { "papa } \\
\text { peruanita" }\end{array}$ & $\begin{array}{l}\text { hierba de } \\
1 \text { metro }\end{array}$ & terrenos de cultivo & $\begin{array}{l}\text { semilla y } \\
\text { esquejes }\end{array}$ & tubérculo & $\mathrm{AH}$ & 32 & 0.34 \\
\hline 113 & $\begin{array}{l}\text { Solanum tuberosum L. } \\
\text { (SOLANACEAE) }\end{array}$ & "papa huayro" & $\begin{array}{l}\text { hierba de } \\
1 \text { metro }\end{array}$ & terrenos de cultivo & $\begin{array}{l}\text { semillas y } \\
\text { esquejes }\end{array}$ & tubérculo & $\mathrm{AH}$ & 11 & 0.12 \\
\hline 114 & $\begin{array}{l}\text { Soleirolia soleirolii (Req.) } \\
\text { Dandy (URTICACEAE) }\end{array}$ & $\begin{array}{l}\text { "mosquito", } \\
\text { "lagrimitas" }\end{array}$ & $\begin{array}{l}\text { hierba de } 25 \\
\text { centímetros }\end{array}$ & $\begin{array}{l}\text { terrenos sombrea- } \\
\text { dos y húmedos }\end{array}$ & semillas & $\begin{array}{l}\text { hojas y } \\
\text { flores }\end{array}$ & $\mathrm{OR}$ & 29 & 0.31 \\
\hline 115 & $\begin{array}{l}\text { Sonchus oleraceus (L.) L. } \\
\text { (COMPOSITAE) }\end{array}$ & "cerraja" & $\begin{array}{l}\text { hierba de hasta } \\
\quad 1 \text { metro }\end{array}$ & $\begin{array}{l}\text { terrenos húmedos } \\
\text { y alrededor de los } \\
\text { terrenos de cultivo }\end{array}$ & $\begin{array}{l}\text { semillas y } \\
\text { rizomas }\end{array}$ & hojas & M & 12 & 0.13 \\
\hline 116 & $\begin{array}{l}\text { Spondias purpurea L. } \\
\text { (ANACARDIACEAE) }\end{array}$ & "ciruela" & $\begin{array}{l}\text { árbol de } \\
5 \text { metros }\end{array}$ & $\begin{array}{c}\text { terrenos } \\
\text { pedregosos y secos }\end{array}$ & semillas & fruto & $\mathrm{AH}$ & 34 & 0.36 \\
\hline 117 & $\begin{array}{c}\text { Taraxacum campylodes } \\
\text { G.E.Haglund } \\
\text { (COMPOSITAE) }\end{array}$ & $\begin{array}{l}\text { "diente de } \\
\text { león" }\end{array}$ & $\begin{array}{l}\text { hierba de } 30 \\
\text { centímetros }\end{array}$ & terrenos de cultivo & semillas & hojas & $\mathrm{AH}$ & 57 & 0.61 \\
\hline 118 & $\begin{array}{l}\text { Thymus vulgaris L. } \\
\text { (LAMIACEAE) }\end{array}$ & "tomillo" & $\begin{array}{l}\text { arbusto de } 40 \\
\text { centímetros }\end{array}$ & $\begin{array}{l}\text { terrenos secos y } \\
\text { rocosos }\end{array}$ & $\begin{array}{l}\text { semillas y } \\
\text { esquejes }\end{array}$ & hojas & $\mathrm{AH}, \mathrm{M}$ & 51 & 0.54 \\
\hline 119 & $\begin{array}{l}\text { Tiquilia paronychioides } \\
\text { (Phil.) A.T. Richardson } \\
\text { (BORAGINACEAE) }\end{array}$ & "flor de arena" & hierba postrada & $\begin{array}{c}\text { terrenos secos, laderas } \\
\text { de los cerros y terrenos } \\
\text { de cultivo }\end{array}$ & semilla & $\begin{array}{l}\text { flores y } \\
\text { hojas }\end{array}$ & M & 31 & 0.33 \\
\hline 120 & $\begin{array}{l}\text { Trichilia hirta L. } \\
\text { (MELIACEAE) }\end{array}$ & $\begin{array}{l}\text { "cabo de } \\
\text { hacha", "mata } \\
\text { piojos" }\end{array}$ & $\begin{array}{l}\text { árbol de } \\
10 \text { metros }\end{array}$ & $\begin{array}{l}\text { terrenos secos } \\
\text { y laderas de los } \\
\text { cerros }\end{array}$ & $\begin{array}{l}\text { semillas y } \\
\text { esquejes }\end{array}$ & frutos & MA & 3 & 0.03 \\
\hline 121 & $\begin{array}{l}\text { Triticum aestivum L. } \\
\quad \text { (POACEAE) }\end{array}$ & "trigo" & $\begin{array}{l}\text { hierba de } \\
1 \text { metro }\end{array}$ & terrenos de cultivo & semillas & granos & $\mathrm{AH}$ & 49 & 0.52 \\
\hline 122 & $\begin{array}{c}\text { Vaccinium corymbosum L. } \\
\text { (ERICACEAE) }\end{array}$ & "arándano" & $\begin{array}{l}\text { arbusto de } \\
1 \text { metro }\end{array}$ & terrenos de cultivo & semillas & frutos & $\mathrm{AH}$ & 60 & 0.64 \\
\hline 123 & $\begin{array}{l}\text { Vitis vinifera } \mathrm{L} . \\
\text { (VITACEAE) }\end{array}$ & "uva" & $\begin{array}{l}\text { arbusto } \\
\text { trepador }\end{array}$ & terrenos de cultivo & semilla & fruto & $\mathrm{AH}$ & 52 & 0.55 \\
\hline 124 & $\begin{array}{l}\text { Zea mays L. } \\
\text { (POACEAE) }\end{array}$ & "maíz" & $\begin{array}{l}\text { hierba de } \\
3 \text { metros }\end{array}$ & terrenos de cultivo & semillas & granos & $\mathrm{AA}, \mathrm{AH}$ & 140 & 1.49 \\
\hline 125 & $\begin{array}{l}\text { Zingiber officinale Roscoe } \\
\text { (ZINGIBERACEAE) }\end{array}$ & "kion" & $\begin{array}{l}\text { arbusto de } \\
1 \text { metro }\end{array}$ & terrenos de cultivo & $\begin{array}{l}\text { semillas y } \\
\text { rizomas }\end{array}$ & rizomas & $\mathrm{AH}, \mathrm{M}$ & 140 & 1.49 \\
\hline
\end{tabular}

F.P= Forma de Propagación; P.U= Parte utilizada; C.U= Categoría de uso; R.U= Reporte de uso; I.C = índice Cultural; AA= Alimentación Animal; $\mathrm{AH}=$ Alimentación Humana; $\mathrm{AH}$ (B)=Alimentación Humana (Bebidas); $\mathrm{M}=$ Medicinal; $\mathrm{MA}=$ Madereras; UC = Usos culturales; $\mathrm{OR}=$ Ornamental; $U \mathrm{H}=$ Utensilios y Herramientas; $\mathrm{C}=$ Combustible; $\mathrm{O}(\mathrm{R})=$ Otros (Recreativo); RU: Reporte de Uso; IC: Índice Cultural. 
Así mismo, se puede observar en la Figura 2, de las 6154 menciones de uso de los pobladores del distrito de Simbal, el 5.48\% (337) corresponden a la categoría Alimentación Animal (AA), mientas que $55.41 \%$ (3410) pertenecen a la categoría Alimentación Humana $(\mathrm{AH})$, asimismo 15.92 $\%$ (980) caen en la categoría Medicinal (M), además $5.02 \%$ (309) pertenecen a la categoría Madereras (MA), $0.65 \%$ (40) pertenecen a la categoría de Usos Culturales (UC), $11.59 \%$
(713) recaen en la categoría Ornamentales (OR), asimismo $2.34 \%$ (144) corresponden a la categoría Utensilios y herramientas (UH), otro $3.38 \%$ (208) pertenecen a la categoría de Combustibles (C) y finalmente $0.21 \%$ (13) corresponden a la categoría Otros (0); lo que refleja la gran importancia que le da el poblador del distrito de Simbal al sector alimenticio, explorando la gran diversidad de las especies nutritivas que tiene a su disposición.



Figura 2. Mención de usos (\%) y número de especies (\%) relacionadas con las Categorías de uso del distrito de Simbal, Trujillo, La Libertad, Perú

\section{CONCLUSIONES}

El poblador del distrito de Simbal refiere emplear 125 especies de plantas, enmarcadas dentro de 9 categorías de uso; las cuales a su vez se encuentran distribuidas en 104 géneros y 45 familias, donde las Leguminosae (14 especies), Solanaceae (11 especies), Compositae (8 especies), Poaceae (8 especies) fueron las más representativas por su número de especies.

Las especies de flora más importantes para la Comunidad de Simbal son: Zea mays "maiz", Pinus patula "pino", Zingiber officinale "kion", Allium sativum "ajo", Melia azedarach "cinnamon", Opuntia ficus-indica "tuna", Piper aduncum "matico", Persea americana "palta", Matricaria chamomilla "manzanilla" y Rosmarinus officinalis "romero".

\section{REFERENCIAS BIBLIOGRÁFICAS}

Alipio, A., Mostacero, J., López, E., De La Cruz, A., \& Gil, A. (2020). Valor de uso etnomedicinal de la flora del Cerro "La Botica" empleada por la Comunidad Andina de Cachicadán - Perú. Boletín Latinoamericano y del Caribe de plantas medicinales y aromáticas, 19(6):601613. DOl: https://doi.org/10.37360/ blacpma.20.19.6.43

Amjad, M. (2015). Ethnobotanical profiling and floristic diversity of Bana Valley, Kotli 
(Azad Jammu and Kashmir), Asian Pacific Journal of Tropical Biomedicine, 5(4), 292 299. DOl: http://dx.doi.org/10.1016/S22211691(15)30348-8

Ancajima, R. (1993). Análisis de Alternativas de Planificación de Cultivos mediante Programación Lineal. Caso CHAVIMOCHIC - Sector 1. [Tesis de pre grado], Universidad Nacional Agraria La Molina, Perú. Disponible en: https:// agris.fao.org/agris-search/search. do?recordID=PE19950127626

Arias, D, Kiyamu, C, Pastor, Y, Reyes, P, \& Vallejos, O. (2018). Planeamiento Estratégico para la Industria del Maíz Peruano. [Tesis de maestría]. Pontificia Universidad Católica del Perú, Lima, Perú. Disponible en: http://hdl.handle. net/20.500.12404/11635

Bailey, K. (1994). Methods of Social Research, Fourth Edition, New York: The Free Press.

Barces, O. (1989). Estudio de Mejoramiento de la Infraestructura de la Campiña de Moche. [Tesis de pregrado]. Universidad Nacional Agraria La Molina, Perú.

Barreno, F. (2012). Estudio etnobotánico medicinal en 11 municipios de la reserva de usos múltiples cuenca del lago de Atitlan, Solola. [Tesis de pregrado], Universidad De San Carlos De Guatemala, Guatemala. Disponible en: https:// biblioteca-farmacia.usac.edu.gt/library/ index.php?title=3615\&lang=es\&query=@ title=Special:GSMSearchPage@ process=@autor=VILLAR,\%20LUIS\%20@ mode $=$ \&recnum $=4$

Bocanegra, L., Bocanegra, F. \& Mostacero, J. (2011). Efectividad de la medicina herbolaria y su impacto en la calidad de vida de los pobladores de Curgos, Perú. UCV - Sciéntia, 3(1), 23-34. Disponible en: https://dialnet.unirioja.es/servlet/ articulo?codigo $=6181478$
Brack, A. (2013). La biodiversidad del Perú y su importancia estratégica. Disponible en: http://www.ambperou.fr/index. php? module=articles\&controller =article\&action=show\&id=15.

Brako, L., \& Zarucchi, J. (1993). Catálogo de las Angiospermas y Gimnospermas del Perú. Monografías del Missouri Botánical Garden. Vol. 45.

Briceño, J. \& Billman, B. (2009). Proyecto Arqueológico Cerro Oreja, valle de Moche. Temporada 2007-2008. Informe Final. Informe presentado al Instituto Nacional de Cultura.

Briceño, J. \& Billman, B. (2012). La Ocupación Salinar en la Subcuenca del rio Sinsicap, arte alta del valle de Moche. Investigaciones Sociales, 16(28), 197-222. DOl: https://doi.org/10.15381/ is.v16i28.7398

Britto, B. (2017). Actualización de las Ecorregiones Terrestres dePerúpropuestas en el Libro Rojo de Plantas Endémicas del Perú. Gayana. Botánica. 74(1), 1529. Disponible en: https://biblat.unam. $\mathrm{mx} / \mathrm{es} / \mathrm{revista/gayana-botanica/articulo/}$ actualizacion-de-las-ecorregionesterrestres-de-peru-propuestas-en-ellibro-rojo-de-plantas-endemicas-del-peru

Calderón, J. (2011). Caracterización fitoquímica, actividad antibacteriana y antioxidante de extractos de plantas medicinales utilizadas en Pereira y Santa Rosa de Cabal (Risaralda). [Tesis de pregrado]. Universidad Tecnológica de Pereira, Colombia. Disponible en: http://repositorio.utp.edu.co/dspace/ handle/11059/2265

Caniago, S. \& Siebert, S. (1998). Medicinal plants ecology, knowledge and conservation in Kalimantan. Indonesia, Economic Botany. 52, 229-250.

DOI: https://doi.org/10.1007/BF02862141 
Casas, A., Torres, I., Parra, F. \& Torres, J. (2019). Centros deorigen y diversificación de plantas cultivadas en América. Universidad Nacional Autónoma de México (UNAM). Disponible en: https://www.researchgate. net/publication/336107495_CENTROS_ DE_ORIGEN_Y_DIVERSIFICACION_DE_ PLANTAS_CULTIVADAS_EN_AMERICA

Castañeda, R. \& Albán, J. (2016). Importancia cultural de la flora silvestre del distrito de Pamparomás, Ancash, Perú. Ecología Aplicada, 15(2). DOI: http://dx.doi. org/10.21704/rea.v15i2.755

Constanza, R., D'Arge, R., de Groot, R., Farber, S., Grasso, M., Hannon, B., Limburg, K., Naeem, S., O'Neil, R., Paruelo, J., Raskin, R., Sutton, P. \& Van Den Belt, M. (1997): "The value of the world's ecosystem services and natural capital". Nature, 387, 253-260. DOl: https://doi.org/10.1038/387253a0

De La Cruz, A. \& Mostacero, J. (2019). Uso de plantas medicinales para la cura de enfermedades y/o dolencias: El caso del poblador de la provincia de Trujillo, Perú. Manglar, 16(2): 119-124. DOI: http://dx.doi. org/10.17268/manglar.2019.017

De La Cruz, A. \& Mostacero, J. (2020). Efectividad e impacto de plantas medicinales sobre calidad de vida desde la percepción del poblador, Trujillo, La Libertad, Perú, 2020. [Tesis de doctorado]. Universidad Nacional de Trujillo, Perú. DOI: https://doi.org/10.17268/agroind. sci.2020.02.09

Diamond, J. (2002). Evolution, consequences and future of plant and animal domestication. Nature, 418, 700-707. DOl: https://doi.org/10.1038/ nature01019

Ford, R. (1978). Introduction. The nature and the status of ethnobotany. En Ford $\mathrm{R}$ (Ed.), Anthropological Paper $\mathrm{N}^{\circ} 67$, University of Michigan. Ann Arbor, 29-32. Disponible en: https://www.press.umich. edu/11396367/nature_and_status_of_ ethnobotany_2nd_ed

Google. (s. f.). Mapa del distrito de Simbal, provincia de Trujillo, región La Libertad. DePeru.Com. Disponible en: https://mapas. deperu.com/la-libertad/trujillo/simbal/

Gomez - Beloz, A. (2002). Plant use Knowledge of the Winikina Warao: The case for questionnaires in ethnobotany. Economic Botany, 56(3), 231-242. Disponible en: https://www.jstor.org/ stable/4256576

Gonzáles, A. (2001). Etnobotánica de frutales nativos en comunidades de la cuenca baja del rio Ucayali, Perú. IIAP, 139 p.

Hill, C. (2011). An Introduction to Sustainable Resource Use. Routledge, 256. Disponible en: https://www.routledge.com/ An-Introduction-to-Sustainable-ResourceUse/Hill/p/book/9781844079278

Idolo, M., Motti, R. \& Mazzoleni, S. (2010). Ethnobotanical and phytomedicinal knowledge in a long-history protected area the Abruzzo, Lazio and Molise National Park (Italian Apennines). Journal of Ethnopharmacology, 127(2), 379-395. DOI: 10.1016/j.jep.2009.10.027

INEI. (2018). Perú: crecimiento y distribución de la población total, 2017. Disponible en: https://www.inei.gob.pe/ media/MenuRecursivo/publicaciones_ digitales/Est/Lib1530/libro.pdf

La Torre, M. \& Albán, J. (2006). Etnobotánica en los Andes del Perú. Botánica Económica de los Andes Centrales, 239-245.

Disponible en: https://www.researchgate. net / public ation / 290436223 . Etnobotanica_en_los_Andes_del_Peru

León, B., Pitman, N. \& Roque, J. (2006). Introducción a las plantas endémicas del Perú. Revista Peruana de Biologia. 13(2), 9-22. DOl: https://doi.org/10.15381/rpb. v13i2.1782 
Medina, D. (2011). Domesticación de las Plantas Cultivadas. Perú: CONCYTEC. Disponible en: http://biblioteca. unsch.edu.pe/cgi-bin/koha/opacdetail.pl? biblionumber $=1115$

Mostacero, J., Castillo, F., Mejía, F., Gamarra, O., Charcape, J. \& Ramírez, R. (2011). Plantas Medicinales del Perú: Taxonomía, Ecogeografía, Fenología y Etnobotánica. Asamblea Nacional de Rectores Fondo Editorial. Disponible en: https://www.Libreriasur.com.pe/Libro/ plantas-medicinales-del-peru_89332

Mostacero, J., De La Cruz-Castillo, J., Lopéz-Medina, E., Gil-Rivera, A. \& Alfaro-Aguirre, E. (2020). Efecto de la medicina herbolaria en la calidad de vida: inventario de especies etnomedicinales y percepción del poblador de Laredo, Perú. Agroindustrial Science, 10(2): 181-190. DOl: $\quad$ https://doi.org/10.17268/agroind. sci.2020.02.09

Mostacero, J., Mejía, F. \& Gamarra, 0. (2009). Fanerógamas del Perú: Taxonomía, utilidad y eco geografía. CONCYTEC. Disponible en: https://www.worldcat.org/ title/fanerogamas-del-peru-taxonomiautilidad-y-ecogeografia/oclc/759119214

Mostacero, J., Mejía, F., Gastañadui, D. \& De la Cruz, J. (2017). Inventario taxonómico, fitogeográfico y etnobotánico de frutales nativos del norte del Perú. Scientia Agropecuaria. 8(3), 215-224. DOl: $\quad$ http://dx.doi.org/10.17268/sci. agropecu.2017.03.04.

Mostacero, J., Mejía, F., Zelada, W., \& Medina, C. (2007). Biogeografía del Perú. Asamblea Nacional de Rectores. Disponible en: http://www.librosperuanos.com/libros/ detalle/13698/Biogeografia-del-Peru

Mostacero, J., Peláez, F., Alarcón, N., De La Cruz, A. Alva, R. \& Charcape, M. (2019). Plantas utilizadas para el tratamiento del cáncer expendidas en los principales mercados de la provincia de Trujillo, Perú,
2016-2017. Boletín Latinoamericano y del Caribe Plantas Medicinales y Aromaticas, 18(1), 81-94. Disponible en: https:// biblat.unam.mx/es/revista/boletinlatinoamericano-y-del-caribe-de-plantasmedicinales-y-aromaticas/articulo/ plantas-utilizadas-para-el-tratamientodel-cancer-expendidas-en-los-principalesmercados-de-la-provincia-de-trujilloperu-2016-2017

Padilla, S. (2013). Evaluación de la biodiversidad y caracterización ecológica de la comunidad vegetal de la campiña de Simbal, La Libertad entre Junio y Julio del 2012. SCIÉNDO, 16(1), 37-51. Disponible en: https://revistas.unitru.edu.pe/index. php/SCIENDO/article/view/627

Paniagua, N., Macía, M. \& Cámara, R. (2010). Toma de datos etnobotánicos de palmeras y variables socioeconómicas en comunidades rurales. Ecología en Bolivia. 45(3): 44-68. Disponible en: https://ecologiaenbolivia.com/documents/ PaniaguaFinal453.pdf

Ramírez, L., Mostacero, J., López, E., De La Cruz, A. \& Gil, A. (2020). Aspectos etnobotánicos de Cuspón, Perú: Una comunidad campesina que utiliza 57 especies de plantas en sus diversas necesidades. Scientia Agropecuaria, 11(1): 7 - 14. DOI: https://dx.doi.org/10.17268/sci. agropecu.2020.01.01

Rodríguez, D. (2014). Especias locales que contribuyen a la oferta turística gastronómica del distrito de Simbal, provincia de Trujillo, región La Libertad. [Tesis pregrado]. Universidad Nacional de Trujillo, Perú. Disponible en: http://dspace. unitru.edu.pe/handle/UNITRU/2491

Rodríguez, E., J. Briceño; B. Billman; A. Boswell; M. Morillo; K. Monzón; B. Martínez; J.. Lujan; K. Burgos; V. Liza; L. Bernabé \& C. Ramírez. (2016). Flora vascular de Collambay (Simbal, Trujillo, La Libertad, Perú). Libro de Resúmenes del XV Congreso Nacional de Botánica, Cusco, 
Perú, 10-13 mayo 2016. Pág. 154.

Rostworowski, M. (1979). La costa peruana prehispánica. Revista de la Universidad Complutense, 28(117), 461-473. Disponible en: https://dialnet.unirioja.es/ ejemplar/138142

Sagástegui A., Dillon M., Sánchez I., Gonzáles S. \& Asencio A. (1999). Diversidad Florística del Norte del Perú. Tomo I, WWF, Universidad Privada Antenor Orrego. Disponible en: http://www.sacha.org/envir/ peru/peru_sp.htm

Sánchez, I. (2011). Especies medicinales de Cajamarca I: contribución etnobotánica, morfológica y taxonómica. Universidad Privada Antonio Guillermo Urrelo, Lumina Cooper Fondo Editorial, 227. Disponible en: http://biblioteca.cultura. pe:8020/cgi-bin/koha/opac-detail. pl?biblionumber $=5555$ \& shelfbrowse itemnumber $=9297$

Sanjinés, A., Ollgaard, B. \& Henrik, B. (2006). Frutos Comestibles, Botánica Económica de Los Andes Centrales; Universidad Mayor de San Andrés, 329-346. Disponible en: https://beisa.au.dk/Publications/BEISA \%20Book \%20pdfer/Capitulo \%2021.pdf

Sheldon,W., Balick, M., Laird, S., \& Milne, G. (1997). Medicinal Plants: Can Utilization and Conservation Coexist?. Advances in Economic Botany, 12, i-104. Disponible en: http://www.jstor.org/stable/43931401

Smith, A., León, B., Tuomisto, $H_{\text {., }}$ Van der Werff, H., Moran, R., Lehnert, M. \& Kessler, M. (2005). New records of pteridophytes for the flora of Peru. SIDA, 21(4), 2321-2342. DOI: https://doi.org/10.2307/41968530

Tardío, J. \& Pardo de Santayana, M. (2008). Cultural importance indices: a comparative analysis based on the useful wild plants of southern Cantabria (Northern Spain). Economic Botany. 62, 24-39. DOl: https:// doi.org/10.1007/s12231-007-9004-5
Ulloa, C., Acevedo, R., Beck, S., Belgrano, M., Bernal, R., Berry, P., Brako, L., Celis, M., Davidse, G., Forzza, R., Gradstein, S., Hokche, O., León, B., León, S., Magill, R., Neill, D., Nee, M., Raven, P., Stimmel, H., Strong, M., Villaseñor, J., Zarucchi, J., Zuloaga, F. \& Jørgensen, P. (2017). An integrated assessment of the vascular plant species of the Americas. Science, 358(6370), 1614-1617. DOl: https://doi. org/10.1126/science.aao0398

Ulloa, C., Zarucchi, J. \& León, B. (2004). Diez Años de Adiciones a la flora del Perú: 1993-2003. Arnaldoa, Ed. Especial, 1-242. Disponible en: http://www.mobot. org/MOBOT/research/peru/diez_a \%C3 \%Blos_per \%C3 \%BA.shtml

Weigend, M. (2004). Additional observations on the biogeography of the Amotape-Huancabamba zone in Northern Perú: Defining the South-Eastern limits. Revista Peruana de Biología. 11(2), 127134. Disponible en: http://dev.scielo.org.pe/ scielo.php?script=sci_arttext\&pid=S172799332004000200003\&lng=en\&tlng=es. 